\title{
Amelogenesis imperfecta with multiple impacted teeth and altered eruption pathways - A radiographic case report
}

\author{
SADJ June 2020, Vol. 75 No. 5 p262 - p266
}

C Nel', Z Yakoob², T Kungoane ${ }^{3}$, CL Davidson ${ }^{4}$

\begin{abstract}
Amelogenesis imperfecta (Al) comprises a vast group of developmental alterations in the quantity and/or quality of enamel, unaffected by systemic disorders.
\end{abstract}

In this case report we describe the typical clinical and radiographic features of $\mathrm{Al}$ with multiple impacted teeth and altered eruption pathways. Patients with Al benefit from early diagnosis and treatment to prevent tooth loss and loss of vertical dimension.

Optimal management of these patients requires a multidisciplinary approach and regular dental recall appointments. Therefore it is the oral health clinician's responsibility for the timeous identification of this condition.

\section{Author affiliations:}

1. Chané Nel: $B C h D, M S c($ Rad)., University of Pretoria, Oral and Dental Hospital, Corner of Bophelo and Steve Biko Roads, Pretoria, South Africa.

ORCID Number: 0000-0003-4047-6356

2. Zarah Yakoob: $B C h D, P D D$ (Rad), Msc (Rad), University of Pretoria, Oral and Dental Hospital, Corner of Bophelo and Steve Biko Roads, Pretoria, South Africa.

ORCID Number: 0000-0003-1966-5574

3. Tsholofelo Kungoane: $B$ Dent Ther, BDS, MSc (Oral Path), FC SA (PATH) ORAL, MDENT (Oral Path), University of Pretoria, Oral and Dental Hospital, Corner of Bophelo and Steve Biko Roads, Pretoria, South Africa.

ORCID Number: 0000-0003-4312-7418

4. Christy L Davidson: BChD, PGDipDent (Endo), MSc (Oral Bio), University of Pretoria, Oral and Dental Hospital, Corner of Bophelo and Steve Biko Roads, Pretoria. ORCID Number: 0000-0002-3638-6932

Corresponding author: Christy L Davidson

University of Pretoria, Oral and Dental Hospital, Corner of Bophelo and Steve Biko Roads, Pretoria.

Email: christy.davidson@up.ac.za

Author contributions:

1. Chané Nel: Conception and design of the manuscript. Drafted and revised the work critically for important intellectual content $-30 \%$

2. Zarah Yakoob: Conception and design of the manuscript. Drafted and revised the work critically for important intellectual content $-30 \%$

3. Tsholofelo Kungoane: Pathological diagnosis and tooth ground section - $10 \%$

4. Christy L Davidson: Conception and design of the manuscript. Drafted and revised the work critically for important intellectual content $-30 \%$

All authors approved of the version to be published; and agreed to be accountable for all aspects of the work in ensuring that questions related to the accuracy or integrity of any part of the work are appropriately investigated and resolved.

\section{Keywords}

Amelogenesis imperfecta, impactions, altered eruption pathways, gubernacular canals.

\section{INTRODUCTION}

Amelogenesis imperfecta (Al) comprises a vast group of developmental alterations in the quantity and/or quality of enamel, unaffected by systemic disorders. To date over 15 genetic mutations have been identified in cases of non-syndromic Al. ${ }^{1-6}$ A recent publication hypothesised that gene mutations in ENAM and AMELX leads to endoplasmic reticulum stress in ameloblasts which in turn activates an unfolded protein response as a pathogenic mechanism for $\mathrm{Al}^{7}$

Additionally, for reasons not yet fully understood, defects in acid phosphatase and RELT, have been implicated in Al. ${ }^{8-11}$ Several other mutations have been identified in syndromic cases with $\mathrm{Al}$, including DLX3 (trichodento-osseous syndrome) and FAM20A (enamel-renal syndrome, amelogenesis imperfecta-gingival fibromatosis syndrome)..$^{12-14}$

Four phenotypic subtypes of $\mathrm{Al}$ are recognised; hypoplastic, hypocalcified, hypomatured and mixed hypomatured/hypoplastic in combination with taurodontism. ${ }^{15-17}$ In the hypoplastic subtype, the disruption occurs in the deposition of the enamel resulting in a thin band of fully mineralised enamel or pits and grooves dispersed in normal enamel thickness.

The hypocalcified subtype encompasses presentations where the full thickness of enamel is deposited but no mineralisation occurs. Only partial mineralisation occurs in the hypomatured subtype. ${ }^{17,18}$ This classification is however limited, as both qualitative and quantitative enamel defects may co-present within the same patient. ${ }^{18,19}$

The diagnosis of $\mathrm{Al}$ is largely based on characteristic clinical and radiographic findings. ${ }^{17,20}$ In normal circumstances enamel has a higher radiographic density when compared to dentine due to the higher mineral content. ${ }^{21}$ In the hypoplastic subtype, a thin band of radiopaque enamel can be distinguished from the less radiopaque dentine. With hypomatured Al the radiographic density of enamel and dentine is alike, whereas in the hypo- 
calcified subtype the enamel will have a lower density than that of the dentine and may not be evident on a radiograph. ${ }^{17}$

The primary clinical concerns of $\mathrm{Al}$ include increased dentinal sensitivity, altered aesthetics, loss of vertical dimension, malocclusion and increased caries susceptibility. ${ }^{17,22}$ Other dental features that have been reported in association with $\mathrm{Al}$ include pulpal calcifications, root malformations (including taurodontism) and impactions of permanent teeth. ${ }^{20,23,24}$ In this case report we describe a patient that presented with all the typical radiographic features of $\mathrm{Al}$, and additional interesting findings.

\section{CASE PRESENTATION}

A 26-year-old male patient presented with the main complaint of small and sensitive teeth. His dental history included the recent construction a maxillary partial denture for improved functionality and composite veneers on the maxillary anterior teeth for aesthetics.

No familial history of similar conditions were reported. Extraoral examination revealed recurrent Herpes labialis on the right bottom lip. Intraorally, generalised tooth wear and numerous retained primary teeth were present.
The maxillary central incisors showed veneer preparations while both maxillary lateral incisors had composite veneers. The permanent first molars displayed a rough and yellow appearance with no visible enamel (Figure 1). The mandibular right second incisor had a distal uncomplicated coronal fracture. The patient's oral hygiene was satisfactory with non-inflammatory gingival enlargement. The patient was referred for radiographic examination.

The panoramic radiograph (Figure 2) revealed a full complement of teeth however only the incisors and first permanent molars were erupted. All the remaining teeth were impacted and no supernumerary teeth were detected. Pulpal calcifications could be seen in some of the erupted and a few of the unerupted teeth. The mandibular right first molar and left second deciduous molar were carious.

The carious mandibular right deciduous molars were associated with periapical radiolucencies. A residual root was visible in the maxillary left first premolar area. Radiographically, there was no distinction between the enamel and dentine in the erupted and unerupted teeth. The impacted teeth demonstrated corticated radiolucent tubular or canal-like structures connecting the dental follicle to the alveolar ridge which resembled eruption pathways.

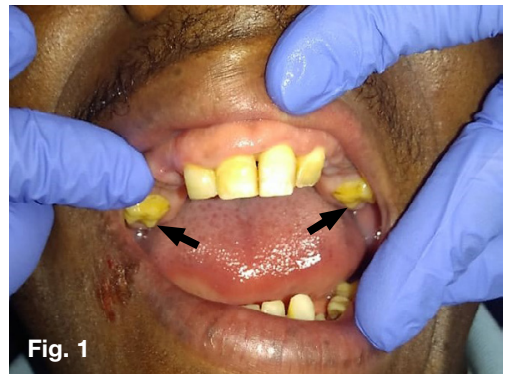

Figure 1. Intraoral photograph showing a lack of enamel and a rough and yellow appearance of the maxillary first molars (black arrows) and multiple missing teeth.

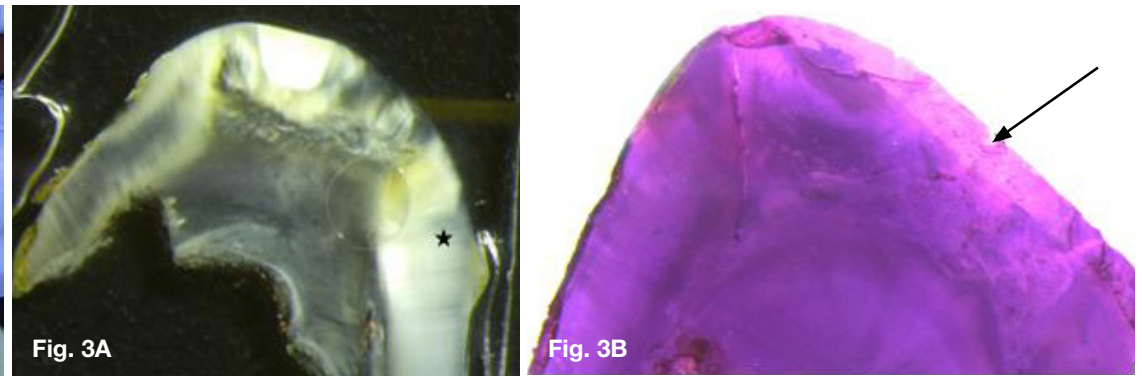

Figure 3. A: Ground section of the mandibular right second deciduous molar showing dentine with dentinal tubules, pulp with pulpal chamber and minimal representation of enamel. B: Haematoxylin and Eosin section of the crown showing the enamel (arrow head).

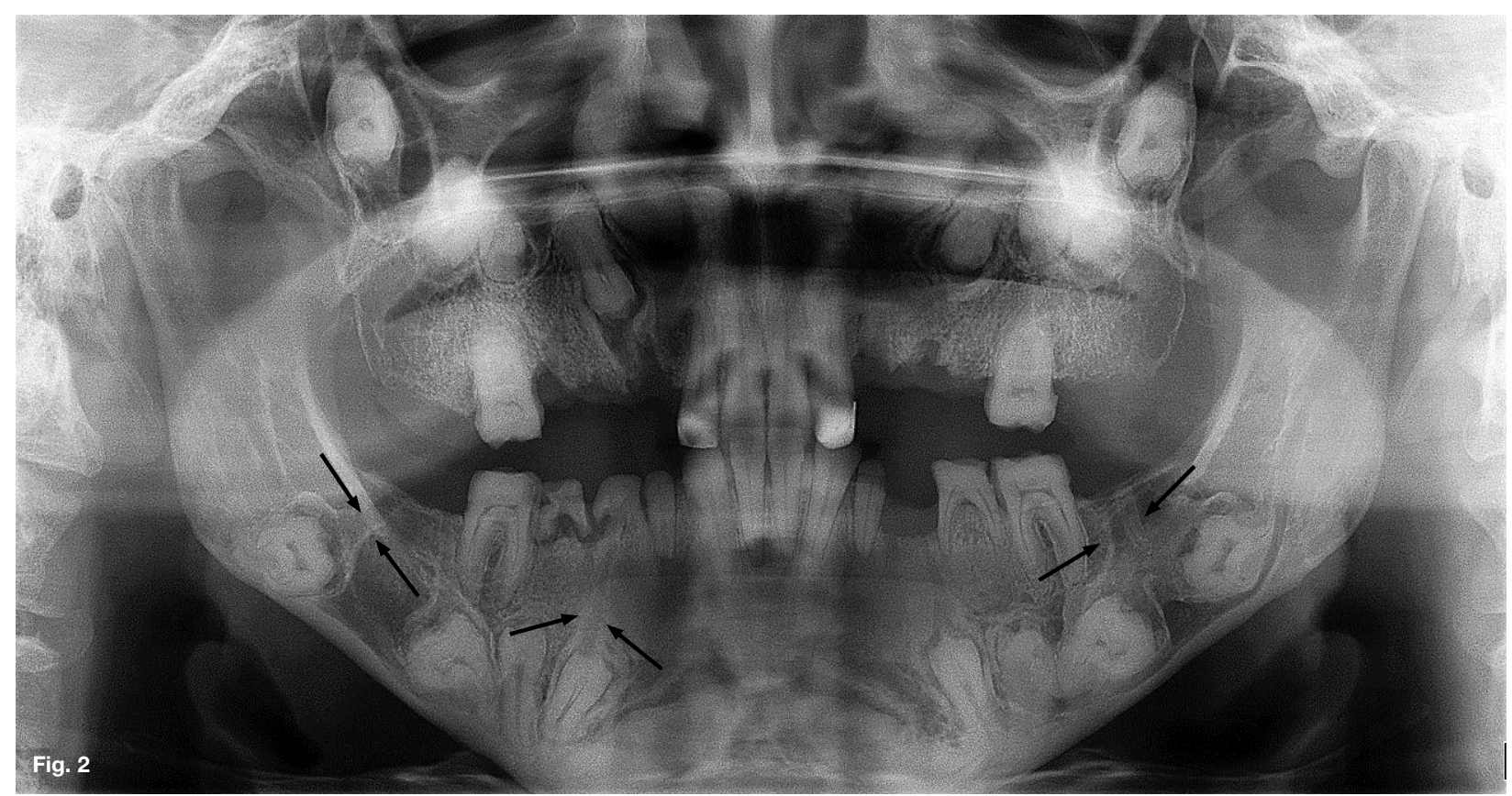

Figure 2. Panoramic radiograph. Presence of numerous impacted teeth showing no visible enamel. Corticated canal-like structures connecting the dental follicle to the alveolar ridge (black arrows). 
The mandibular right deciduous molars were extracted and submitted for histological examination. The ground sections (Figure 3 ) showed molar teeth with minimal representation of enamel. The dentine was of normal architecture with a straight dentine-enamel junction. Both teeth showed focal external root resorption.

These features were in keeping with Al. The patient was referred to the post-graduate prosthodontics department for further management and dental rehabilitation. Genetic testing was declined by the patient. The patient was also referred to a physician for renal analysis to rule out enamel-renal syndrome.

\section{DISCUSSION}

The most apparent features observed on the panoramic radiograph were the numerous impacted teeth and the presence of canal-like eruption pathways connecting the dental follicle to the alveolar ridge. Patients with Al are six times more likely to have impactions of permanent teeth and associated anomalies such as dentigerous cysts. ${ }^{19,23}$

Tooth eruption is a complex developmental process influenced by genetic regulation and growth of the jaws. ${ }^{25}$ The dental follicle orchestrates tooth eruption through the regulation of specific genes regulating bone resorption coronally and deposition apically. ${ }^{26,27}$ Disturbances in this process can be attributed to follicular enlargements or disruptions in the molecular signals of the eruption process itself. ${ }^{19,23}$

Gubernacular canals are bony canals thought to occur as a result of the gubernacular cord. This cord is a fibrous strand remnant of the dental lamina that connects the reduced enamel epithelium surrounding the developing tooth, with the overlying oral epithelium. It secretes epidermal growth factor mediator that promotes osteoclastogenesis, thereby directing tooth eruption through the eruptive pathway. ${ }^{28-31}$

The gubernacular cord was initially only described in association with permanent teeth that have a primary predecessor but later found to also be associated with permanent molars that do not have primary predecessors. ${ }^{28,32,33}$ However, the existence of the gubernacular cord and canal remains controversial. Nishida et al. reported the gubernacular canal as "corticated tracts of low density, contiguous with the dental follicle of an unerupted tooth". ${ }^{34}$

A recent study on cone beam computed tomography investigated the presence and morphology of these canals in relation to eruption disturbances and pathologic conditions associated with impacted and unerupted permanent teeth. They found that a disturbed eruption pattern could occur with either the absence or an alteration in the shape of the gubernacular canal. ${ }^{29}$

These eruption pathways have also been observed in cases of primary failure of eruption disorder where a fault in the eruptive mechanism, with no mechanical obstruction, results in impaction. ${ }^{27,35}$ The panoramic radiograph of the presented case shows evidence of altered eruption pathways, suggesting a fault in the eruptive process.

In this case report the patient had presented with noninflammatory gingival enlargement. This finding has previously been reported in the literature as an association with Al. ${ }^{36,37}$ From 1990 to 2014, there have been 8 Al case reports (5 of which originated from South Africa) with dental follicular-like harmatomas and generalised gingival enlargement. $24,38-44$ These reported cases demonstrate a form of $\mathrm{Al}$ together with enlarged dental follicles associated with numerous impacted teeth. ${ }^{24,36,38-44}$ Some of these cases with enlarged follicles were diagnosed as dentigerous cysts ${ }^{36}$ or odontogenic fibromas. ${ }^{38}$ However, one should consider that the latest WHO classification states that pericoronal radiolucencies with central odontogenic fibroma features associated with impacted teeth, should be considered hyperplastic follicles rather than neoplastic. ${ }^{45}$

In this case report, the patient presented with Al, gingival hyperplasia, multiple impactions, hyperplastic follicles and diffuse intrapulpal calcifications. These features have previously been reported in association with FAM20A mutation. ${ }^{13,46}$ However to our knowledge this is the first reported case showing altered eruption pathways of impacted teeth in Al.

Patients with Al benefit from early diagnosis and treatment to prevent consequences of tooth loss and loss of vertical dimension. The increased dentinal sensitivity is caused by the exposed dentinal tubules and can be managed with fluoride application or coverage depending on the extent of enamel disruption. The patients also present with increased caries susceptibility that require preventative dental procedures and regular follow up appointments. The altered aesthetics can be managed with crowns or veneer preparations. Bond strength to the altered enamel should be evaluated on a case to case basis. Direct resin restorations have shown success in the improvement of aesthetics but long term follow-up is needed to validate the longevity of the treatment success. ${ }^{47} \mathrm{~A}$ recent review found that indirect restorative techniques have a better prognosis in the case of $\mathrm{Al}$ as compared to direct restorative techniques. ${ }^{48}$

The optimal management of these patients requires a multidisciplinary approach and regular dental recall appointments. ${ }^{49}$ Therefore, it is the oral health clinician's responsibility for the timeous identification of this condition. A limitation of this study is that the true nature of the dental follicle and associated canals can only be speculated, as there was no indication for surgical removal of the impacted teeth. These lesions will be monitored going forward.

\section{Declaration}

Authors Nel, Yakoob, Kungoane and Davidson declare no conflict of interest.

\section{Ethical considerations}

All procedures followed were in accordance with the ethical standards of the responsible committee on human experimentation (institutional and national) and with the Helsinki Declaration of 1975, as revised in 2008 (5). 
Informed consent was obtained from all patients for being included in the study.

This article does not contain any studies with human or animal subjects performed by the any of the authors.

\section{References}

1. Smith CEL, Poulter JA, Antanaviciute A, Kirkham J, Brookes SJ, Inglehearn CF, et al. Amelogenesis Imperfecta; Genes, Proteins, and Pathways. Front Physiol. 2017; 8: 1-22.

2. Kim YJ, Kim YJ, Kang J, Shin TJ, Hyun HK, Lee SH, et al. A novel AMELX mutation causes hypoplastic amelogenesis imperfecta. Arch Oral Biol. 2017; 76: 61-5.

3. Lu T, Li M, Xu X, Xiong J, Huang C, Zhang X, et al. Whole exome sequencing identifies an $\mathrm{AMBN}$ missense mutation causing severe autosomal-dominant amelogenesis imperfecta and dentin disorders. Int J Oral Sci. 2018; 10(3): 26. Available from: http://dx.doi.org/10.1038/s41368-018-0027-9.

4. Nowwarote $\mathrm{N}$, Theerapanon $\mathrm{T}$, Osathanon $\mathrm{T}$, Pavasant $\mathrm{P}$, Porntaveetus T, Shotelersuk V. Amelogenesis imperfecta: A novel FAM83H mutation and characteristics of periodontal ligament cells. Oral Dis. 2018; 24(8): 1522-31.

5. Xin W, Wenjun W, Man Q, Yuming Z. Novel FAM83H mutations in patients with amelogenesis imperfecta. Sci Rep. 2017; 7(1): 1-9. Available from: http://dx.doi.org/10.1038/ s41598-017-05208-0.

6. Koruyucu M, Kang J, Kim YJ, Seymen F, Kasimoglu Y, Lee ZH et al. Hypoplastic Al with Highly Variable Expressivity Caused by ENAM Mutations. J Dent Res. 2018; 97(9): 1064-9.

7. Brookes SJ, Barron MJ, Smith CEL, Poulter JA, Mighell AJ, Inglehearn CF, et al. Amelogenesis imperfecta caused by $\mathrm{N}$-terminal enamelin point mutations in mice and men is driven by endoplasmic reticulum stress. Hum Mol Genet. 2017; 26(10): 1863-76.

8. Seymen F, Kim YJ, Lee Y, Al E. Recessive mutations in testicular acid phosphatase (ACPT) cause hypoplastic amelogenesis imperfecta. Am J Hum Genet. 2016; 99: 1199-205.

9. Smith CEL, Whitehouse LLE, Poulter JA, Brookes SJ, Day PF, Soldani $F$, et al. Defects in the acid phosphatase ACPT cause recessive hypoplastic amelogenesis imperfecta. Eur $J$ Hum Genet. 2017; 25(8): 10159. Available from: http://dx.doi. org/10.1038/ejhg.2017.79.

10. Kim JW, Zhang H, Seymen F, Koruyucu M, Hu Y, Kang J, et al. Mutations in RELT cause autosomal recessive amelogenesis imperfecta. Clin Genet. 2019; 95(3): 375-83.

11. Hytönen MK, Arumilli M, Sarkiala E, Nieminen P, Lohi H. Canine models of human amelogenesis imperfecta: identification of novel recessive ENAM and ACP4 variants. Hum Genet. 2019; 138(5): 525-33. Available from: http://dx.doi.org/10.1007/s00 439-019-01997-8.

12. Kim YJ, Seymen F, Koruyucu M, Kasimoglu Y, Gencay K, Shin $T J$, et al. Unexpected identification of a recurrent mutation in the DLX3 gene causing amelogenesis imperfecta. Oral Dis. 2016; 22(4): 297-302.

13. Dourado MR, dos Santos CRR, Dumitriu S, lancu D, Albanyan S, Kleta R, et al. Enamel renal syndrome: A novel homozygous FAM20A founder mutation in 5 new Brazilian families. Eur $J$ Med Genet. 2018; (October): 1-7. Available from: https://doi. org/10.1016/j.ejmg.2018.10.013.

14. Koruyucu M, Seymen F, Gencay G, Gencay K, Tuna EB, Shin TJ, et al. Nephrocalcinosis in Amelogenesis Imperfecta Caused by the FAM20A Mutation. Nephron. 2018; 139(2): 189-96.

15. Cobourne MT, Sharpe PT. Diseases of the tooth: the genetic and molecular basis of inherited anomalies affecting the dentition. WIREs Dev Biol. 2013; 2: 183-212.

16. Witkop CJ. Amelogenesis imperfecta, dentinogenesis imperfecta and dentin dysplasia revisited: problems in classification. J Oral Pathol. 1988; 17: 547-53.

17. Sabandal MMI, Schäfer E. Amelogenesis imperfecta: review of diagnostic findings and treatment concepts. Odontology. 2016; 104: 245-56
18. Prasad MK, Laouina S, El Alloussi M, Dollfus H, Bloch-Zupan A. Amelogenesis Imperfecta: 1 Family, 2 Phenotypes, and 2 Mutated Genes. J Dent Res. 2016; 95(13): 1457-63.

19. Reddy SS, Aarthi NV, Harish BN. Hypoplastic amelogenesis imperfecta with multiple impacted teeth - report of two cases. J Clin Exp Dent. 2010; 2(4): 207-2011.

20. Aldred MJ, Savarirayan R, Crawford PJ. Amelogenesis Imperfecta- A classification and catalogue for the $21^{\text {st }}$ century. Oral Dis. 2003; 9: 19-23.

21. Pekkan G, Pekkan K, Hatipoglu M, Tuna S. Comparative radiopacity of ceramics and metals with human and bovine dental tissues. J Prosthet Dent. 2011; 106: 109 -17.

22. Adorno-Farias D, Ortega-Pinto A, Gajardo P, Salazar A, Morales-Bozo I, Werlinger F, et al. Diversity of clinical, radiographic and genealogical findings in 41 families with amelogenesis imperfecta. J Appl Oral Sci. 2019; 27(0): 1-11.

23. Collins MA, Mauriello SM, Tyndall TA, Wright JT. Dental anomalies associated with Amelogenesis imperfecta - A radiographic assessment. Oral Surg Oral Med, Oral Pathol Oral Endol Radiol. 1999; 88: 358-64.

24. O'Connell S, Davies J, Smallridge J, Vaidyanathan M. Amelogenesis imperfecta associated with dental follicular-like hamartomas and generalised gingival enlargement. Eur Arch Paediatr Dent. 2014; 15: 361-8.

25. Nanci A. Ten Cate's Oral Histology: Development, Structure and Function. $9^{\text {th }}$ ed. Elsevier, editor. St. Louis, Missouri; 2018.

26. Wise GE. Cellular and molecular basis of tooth eruption. Orthod Craniofac Res. 2009; 12(2): 67-73.

27. Wise GE, Frazier-Bowers S, D’Souza RN. Cellular, molecular, and genetic determinants of tooth eruption. Crit Rev Oral Biol. 2002; 13(4): 323 - 34

28. Hodson J. The gubernaculum dentis. Dent Pract. 1971; 21(12): 423-8.

29. NagihanKoc HD, BernaCagirankaya L, SemaDural, van der Stelt PF. CBCT assessment of gubernacular canals in relation to eruption disturbance and pathologic condition associated with impacted/unerupted teeth. Oral Surg Oral Med Oral Pathol Oral Radiol. 2019; 127(2): 175 - 84.

30. Ferreira DCA, Fumes, Ana Caroline Consolaro A, NelsonFilho P, Mussolino de Queiroz A, De Rossi A. Gubernacular cord and canal - does these anatomical structures play a role in dental eruption? RSBO. 2013; 10(2167-71).

31. Consolaro A. Orthodontic traction: possible consequences for maxillary canines and adjacent teeth. Dent Press $J$ Orthod. 2010; 15(4): $15-23$.

32. Scott J. The development and function of the dental follicle. Br Dent J. 1948; 85(9): 193 - 9.

33. Dos Santos Moreira F, De Almeida LY, De Oliveira Santos C, Motta ACF, Martínez Martínez M, Machado RA. Gubernacular Cord and Canal. Oral Surg Oral Med Oral Pathol Oral Radiol. 2015; 120(2): e80.

34. Nishida I, Oda M, Tanaka T, Kito S, AI E. Detection and imaging characteristics of the gubernacular tract in children on cone beam and multidetector computed tomography. Oral Maxillofac Radiol. 2015; 120(2): 109-17.

35. Proffit WR, Vig KW. Primary Failure of eruption: A possible cause for posterior open bite. Am J Orthod. 1981; 80(2): 173-90.

36. Poulsen S, Gjørup H, Haubek D, Haukali G, Hintze H, Løvschall $H$, et al. Amelogenesis imperfecta a systematic literature review of associated dental and oro-facial abnormalities and their impact on patients. Acta Odontol Scand. 2008; 66: 193-9.

37. Yaprak E, Suba冈ı MG, Avunduk M, Aykent F. Amelogenesis Imperfecta and Generalized Gingival Overgrowth Resembling Hereditary Gingival Fibromatosis in Siblings: A Case Report. Case Rep Dent. 2012; 2012: 1-6.

38. Van Heerden, W Raubenheimer EJ, Dreyer A, Benn A. Amelogenesis imperfecta: multiple impactions associated with odontogenic fibromas (WHO) type. JDASA. 1990; 45: 467-71. 
39. Peters E, Cohen M, Altini M. Rough hypoplastic amelogenesis imperfecta with follicular hyperplasia. Oral Surg Oral Med Oral Pathol. 1992; 74: 87-92.

40. Raubenheimer E, Noffke C. Central odontogenic fibroma-like tumors, hypodontia, and enamel dysplasia: review of the literature and report of a case. Oral Surg Oral Med Oral Pathol Oral Radiol Endod. 2002; 94(74-7).

41. Paula L, Melo N, Silva Guerra E, Mestrinho D, Acevedo A. Case report of a rare syndrome associating amelogenesis imperfecta and nephrocalcinosis in a consanguineous family. Arch Oral Biol. 2005; 50: 237-42.

42. Feller L, Jadwat $Y$, Bouckaert M, Buskin A, Raubenheimer E. Enamel dysplasia with odontogenic fibroma-like hamartomas: review of the literature and report of a case. Oral Surg Oral Med Oral Pathol Oral Radiol Endod. 2006; 101: 620-4.

43. Martelli-Junior H, Bonan P, Dos Santos L, Al E. Case reports of a new syndrome associating gingival fibromatosis and dental abnormalities in a consanguineous family. J Periodontol. 2008; 79: 12870-96.

44. Roquebert D, A C, Gil del Real P, Al. E. Amelogenesis imperfecta, rough hypoplastic type, dental follicular hamartomas and gingival hyperplasia: report of a case from Central America and review of the literature. Oral Surg Oral Med Oral Pathol Oral Radiol Endod. 2008; 106: 92-8.

45. El-Naggar A, Chan J, Rubin Grandis J, Takata T, Slootweg P. WHO classification of head and neck tumours. $4^{\text {th }}$ ed. Cancer IA for R on, editor. Lyon; 2017. 228-9.

46. O'Sullivan J, Bitu CC, Daly SB, Urquhart JE, Barron MJ, Bhaskar SS, et al. Whole-exome sequencing identifies FAM$20 \mathrm{~A}$ mutations as a cause of amelogenesis imperfecta and gingival hyperplasia syndrome. Am J Hum Genet. 2011; 88(5): $616-20$.

47. Sabatini C, GuzmÁn-Armstrong S. A conservative treatment for amelogenesis imperfecta with direct resin composite restorations: A case report. J Esthet Restor Dent. 2009; 21(3): 161-70.

48. Strauch S, Hahnel S. Restorative Treatment in Patients with Amelogenesis Imperfecta: A Review. J Prosthodont. 2018; 27(7): 618-23.

49. de La Dure-Molla M, Ifi-Naulin C, Fournier BP, Berdal A, Toupenay S, Manière M-C. Amelogenesis imperfecta: therapeutic strategy from primary to permanent dentition across case reports. BMC Oral Health. 2018; 1-8. 